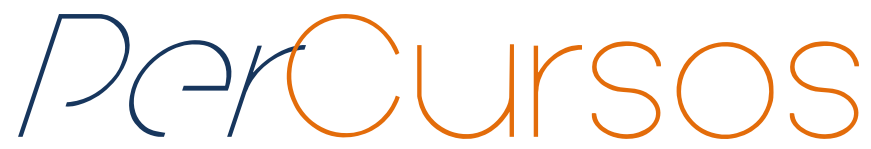

\title{
Povos indígenas, Direitos e Estado: "nosotros, los de entonces, ya no somos los mismos"
}

\begin{abstract}
Resumo
Os processos de mobilizações indígenas que surgiram nas últimas décadas no Brasil e nos demais países latino-americanos têm colocado em evidência aspectos decisivos para a compreensão dos sistemas políticos, econômicos, jurídicos e culturais dominantes. Evidenciam os limites da construção do Estado-Nação como um Estado monocultural, monolinguístico em que os povos indígenas são invisibilizados e estigmatizados. Diante dessas considerações, este trabalho tem entre seus objetivos verificar as relações entre Estado e povos indígenas, frente à emergência destes "novos" atores políticos que buscam o reconhecimento de sua diversidade como povos etnicamente diferenciados, que reivindicam, acima de tudo, sua identidade e dignidade enquanto pessoas humanas diante da extrema violência a que foram submetidos na construção do Estado Nacional. Para a realização deste estudo, faz-se uso de aportes teóricos e metodológicos de várias áreas do conhecimento dentre elas destacam-se: História, Direito e Antropologia.
\end{abstract}

Palavras-chave: Povos Indígenas. Estado. História. Direitos.

\author{
Rosely A. Stefanes Pacheco \\ Doutoranda em História na \\ Universidade Federal da Grande \\ Dourados - UFGD. Doutoranda \\ em Direito na Pontifícia \\ Universidade Católica do Paraná \\ - PUC/PR. Professora da \\ Universidade Estadual de Mato \\ Grosso do Sul - UEMS. \\ Brasil \\ roselystefanes@gmail.com
}

\footnotetext{
Para citar este artigo:

STEFANES PACHECO, Rosely A. Povos indígenas, Direitos e Estado: "nosotros, los de entonces, ya no somos los mismos". Revista PerCursos, Florianópolis, v. 19, n.39, p. 104 - 127, jan./abr. 2018.
}

DOI: $\mathbf{1 0 . 5 9 6 5 / 1 9 8 4 7 2 4 6 1 9 3 9 2 0 1 8 1 0 4}$

http://dx.doi.org/10.5965/1984724619392018104 


\title{
Indigenous peoples, Rights and State: "nosotros, los de entonces, ya no somos los mismos"
}

\begin{abstract}
The processes of indigenous mobilization that have emerged in recent decades in Brazil and other Latin American countries have highlighted decisive aspects for the understanding of the dominant political, economic, legal and cultural systems. They show the limits of the construction of the Nation-State as a monocultural, monolinguistic state where indigenous peoples are invisibilized and stigmatized. In view of these considerations, this work has among its objectives to think about the relations between the State and indigenous peoples, facing the emergence of these "new" political actors who seek the recognition of their diversity as ethnically distinct peoples, who claim, above all, their dignity as persons as regards extreme violence to which they were subjected in the construction of the National State. For the accomplishment of this study we will use theoretical and methodological contributions of several areas of knowledge among which we highlight: History, Law and Anthropology.
\end{abstract}

Keywords: Indigenous Peoples. State. History. Rights. 


\section{Considerações iniciais}

"Os ventos são invisíveis, mas ainda assim o que eles fazem é manifesto para nós e de alguma maneira sentimos sua aproximação." (Hannah Arendt, 1978)

Os processos de mobilizações indígenas que surgiram nas últimas décadas no Brasil e demais nos países latino-americanos têm colocado em evidência aspectos decisivos para a compreensão dos sistemas políticos, econômicos, jurídicos e culturais dominantes. Evidenciam os limites da construção do Estado-Nação como um Estado monocultural, monolinguístico, em que os povos indígenas foram invisibilizados e estigmatizados.

Diante destas considerações, este trabalho tem entre seus objetivos discutir as relações entre Estado e povos indígenas, frente à emergência destes "novos" atores políticos que buscam o reconhecimento de sua diversidade como povos etnicamente diferenciados, que reivindicam, acima de tudo, sua identidade e dignidade enquanto pessoas humanas diante da extrema violência a que foram submetidos na construção do Estado Nacional.

A dignidade enquanto pessoa humana é considera, aqui, conforme a orientação do pesquisador, Ingo W. Sarlet (2015). Este autor conceitua dignidade da pessoa humana como sendo uma "qualidade intrínseca e distintiva de cada ser humano" que o faz merecedor do mesmo respeito e consideração por parte do Estado e da comunidade, implicando, neste sentido, um complexo de direitos e deveres fundamentais que assegurem a pessoa tanto contra todo e qualquer ato de cunho degradante e desumano, como venham a lhe garantir as condições existentes mínimas para uma vida saudável (SARLET, 2015).

Percebe-se que nas dinâmicas reivindicatórias das últimas décadas, os povos indígenas estabelecem parcerias e constroem redes de apoio com organizações não governamentais, organismos multilaterais e com outros setores da sociedade civil, acionando dispositivos e referenciais jurídicos nacionais e internacionais com o objetivo 
de garantir direitos. Neste processo, estes povos ressurgem na América Latina por forças próprias e de importantes aliados, e assim, passam a reconstruir um novo cenário.

\section{Povos indígenas, conquistas e garantias de direitos}

No que diz respeito aos direitos dos povos indígenas, há um novo paradigma de reconhecimento da pluralidade étnica a ser considerado e que está amparado por diversas legislações, normas administrativas, tratados, acordos, declarações e convenções, ratificados pelo Estado brasileiro.

Destacam-se: a Convenção 169, sobre populações tribais em Estados Nacionais da OIT (Organização Internacional do Trabalho), a Declaração das Nações Unidas sobre os direitos dos povos indígenas (ONU), de 2007, e a Declaração Americana sobre os Direitos dos Povos Indígenas (OEA) de 2016, dentre outros instrumento ratificados pelo Brasil, os quais, entre outras disposições, afirmam que todos os povos indígenas são livres e iguais em dignidade e direitos e, em consonância com estas normas internacionais, deve-se reconhecer o direito de todos os indivíduos e povos de se considerarem distintos e de serem respeitados como tais.

Dentre estes documentos, é importante evidenciar a Convenção 169 da OIT, sobre povos indígenas e tribais, adotada em 27 de junho de 1989, em Genebra, na Suíça, e ratificada pelo Brasil em 25 de julho de 2002. Esta Convenção faz parte do amplo movimento de diversidade dos povos de todo o mundo que demandaram perante a OIT seus direitos. De acordo com Souza Filho (2015), esta Convenção reconheceu duas espécies de povos tradicionais a serem protegidos e respeitados: os indígenas, quando suas tradições se estendem para antes da colonização, isto é, aqueles cujos ancestrais já estavam no território quando os não indígenas chegaram; e os tribais, que se constituíram no processo colonizador.

Neste segundo grupo estão inseridos os quilombolas que são produto da colonização escravagista e que no Brasil assumiram uma relevante importância ao terem reconhecidos seus direitos territoriais na Constituição Federal de 1988. No entanto, há muitos outros povos e coletividades que compõem essa complexidade social dos povos 
da floresta e que foram reconhecidos na Magna Carta, dentre eles destacam-se: os extrativistas, como os seringueiros, castanheiros babaçueiros, pescadores e os camponeses como os faxinelenses, geraizeiros, fundos de pasto (SOUZA FILHO, 2015, p. 9).

A Constituição Federal de 1988 reconheceu, por diversos de seus dispositivos, o caráter multiétnico da sociedade brasileira e os direitos de coletividades culturalmente diferenciadas, em especial dos povos indígenas.

Nesta perspectiva, a Constituição Federal de 1988, ao garantir aos povos indígenas o direito ao território e aos seus usos e costumes (art. 231 ss.), e, ao ampliar estas garantias aos remanescentes de quilombos (art. 68 ADCT), dentre outros grupos, inaugura um novo paradigma de reconhecimento da pluralidade étnica, cultural e jurídica da sociedade brasileira.

Portanto, são direitos que não podem ser desconsiderados, haja vista que foram transformados em matéria de ação administrativa para os gestores políticos e públicos brasileiros. Não se trata de mera liberalidade dos poderes da República acatarem ou não tais disposições, pois, já foram reconhecidas pelo Estado brasileiro.

De acordo com Fajardo (2004) e Clavero (2009), durante as últimas décadas temse difundido na América Latina o reconhecimento constitucional do direito indígena, somando-se à subscrição de tratados internacionais. Atualmente, são reconhecidas diversas formas de direitos indígenas, como as Constituições do Panamá, Honduras, Guatemala, Nicarágua, Colômbia, Paraguai, Peru, Argentina, Bolívia, Equador, Venezuela, Brasil, dentre outras.

Por certo, o constitucionalismo emergente em toda a América Latina desde os anos de 1980 supõe várias rupturas epistemológicas e políticas a respeito da relação “Estado, direito e povos indígenas" que haviam sido concebidas até então, dentro de um horizonte monista e monocultural do Estado-Nação (FAJARDO, 2004)1.

\footnotetext{
${ }^{1}$ É de se considerar que mesmo com o reconhecimento da pluralidade étnica, estes países, cada um à sua maneira, têm reconhecido os direitos indígenas de forma distinta. Não podemos colocar todos no mesmo patamar. Alguns, como Bolívia e Equador, apresentam particularidades que vão além dos direitos reconhecidos pelas outras Constituições latino-americanas. Nesse sentido, ver Clavero (2009).
} 
Entre as principais mudanças inseridas nas Cartas Constitucionais dos países destacados anteriormente, podem-se apontar: a ruptura do modelo de Estado-Nação para dar um passo rumo ao Estado pluricultural; a superação do conceito tutelar dos povos indígenas como objetos de políticas para defini-los como sujeitos políticos, ou seja, povos com direitos à autoidentificação e autonomia; a ruptura de um modelo de democracia excludente para um modelo de articulação democrática das diversidades; a ruptura da identidade Estado-direito ou monismo jurídico para abrir campo a um direito que respeite a pluralidade; a superação de um conceito individualista, monocultural e positivista dos direitos humanos para, sobre a base da igual dignidade de culturas, abrir caminho para uma definição e interpretação intercultural dos direitos.

\section{A construção do Estado-Nação e as políticas indigenistas}

No desenvolvimento do processo de ocupação e colonização da América Latina, os povos indígenas foram desconsiderados. A política indigenista foi pensada e efetivada no sentido de anulação de todo o sistema cultural e jurídico indígena já existente. Conforme aponta Slater (2000), o enquadramento do tempo e a ordenação do espaço seguiram uma lógica externamente imposta, cujos efeitos ainda podem ser percebidos no período pós-colonial.

Nesse processo colonizador, foi estimulado o processo de integração dos múltiplos sistemas legais sob o fundamento da igualdade de todos os indivíduos perante uma legislação comum. Não se admitia a existência de grupos sociais com identidades e culturas próprias. Nada de específico poderia haver. Todos deveriam - mesmo que forçosamente - assimilar e viver segundo uma só identidade genérica, integrados à “comunhão” nacional, como se toda a diferença étnica e cultural deixasse de existir e se transformasse numa única cultura homogeneizada (SOUZA FILHO, 2000, STEFANES PACHECO, 2004).

Stavenhagen (2010) enfatiza que, no processo de "conquista" da América, os povos indígenas foram excluídos "no sólo conceptualmente como salvajes y primitivos, no dignos de la civilización que ellos aportaban en su conquista hacia el occidente, sino 
que los exluyeran también juridicamente" (STAVENHAGEN, 2010, p. 17). Portanto, segundo o autor, estes povos foram considerados como aqueles que estavam externos à sociedade, fora da polis, fora do sistema jurídico que tentava impor um modelo de sociedade, e, portanto, deveriam ser tratados como algo estranho ao corpo social, ao corpo cultural, ao corpo civilizado. Neste processo, emerge o conceito de "civilização e barbárie" e começam a gerar políticas de Estado próprias para os povos indígenas.

No Brasil, o Estado foi, pouco a pouco, construindo políticas e institutos jurídicos que pudessem enquadrar as populações concebidas como indígenas, que se encontravam distribuídas pelo território historicamente denominado e imaginado como brasileiro. Certo é que, em toda a América Latina, os direitos dos diversos povos indígenas foram negados e desconsiderados em virtude da aplicação dos princípios jurídicos do Estado-Nação, que Ihes negou a condição de cidadãos(ãs) (SOUZA FILHO, 2000).

Ensaiava-se um discurso de proteção aos direitos indígenas que se repetiria em inúmeras leis, cartas, decretos e alvarás, durante todo o período colonial, monárquico e republicano: situação que somente começaria a mudar com a Constituição de 1988, passando-se do plano teórico para a tentativa de efetivação dos direitos indígenas. Essa proteção era "retórica" porque mesmo com algumas legislações conferindo direitos territoriais aos indígenas, estas não tiveram efetiva aplicação².

Conforme ensina a pesquisadora Manuela Carneiro da Cunha (1992), ainda que se considere que desde fins do século XVII, os direitos dos povos indígenas passaram a ser objeto de leis que Ihes asseguravam uma certa proteção, existia uma grande distância entre o projeto expresso nas Leis e sua aplicabilidade, na medida em que o reconhecimento legal não constituiu de fato um mecanismo seguro e protetor dos direitos indígenas.

Evidencia-se que com a Proclamação da República, em 1889, não se extinguiu de imediato a política indigenista de colônias e diretorias parciais praticada no Império, mas sua atuação desacelerou rapidamente e, por volta de 1893, já não havia mais sinais de seu

\footnotetext{
${ }^{2}$ Sobre o discurso de proteção aos direitos indígenas, ver CUNHA, Manuela Carneiro da Cunha, 1992, SOUZA FILHO, 2000.
} 
funcionamento. Ainda assim, não surgiu outra legislação para preencher este "vazio". Neste processo, a Constituição de 1891, apesar dos esforços da Igreja do Apostolado Positivista Brasileiro, não tratou do assunto - índios - e também nada apresentou para servir de base a uma legislação indigenista.

Somente no ano de 1910, sob pressão de grupos positivistas e como resposta às acusações internacionais de que o governo brasileiro fazia vista grossa aos massacres perpetrados aos povos Coroados (os atuais Kaingang e Xokleng), no Paraná e em Santa Catarina - a dificuldade de lidar com os Kaingang que resistiam e eram acusados de atacar os trabalhadores da Estrada de Ferro Noroeste do Brasil, que atravessava seu território em direção à cidade de Campo Grande, à época Estado de Mato Grosso -, é que o governo republicano irá finalmente instituir sua política indigenista através da criação do SPI (Serviço de Proteção ao Índio), pelo Decreto nº 8.072.

Inicialmente, o SPI administrou a questão indígena a partir de leis e regulamentos que só foram ganhar respaldo constitucional a partir da Constituição de 1934. O primeiro regulamento interno do SPI consta no próprio ato de sua criação e diz respeito à filosofia geral do órgão indigenista, ao modo geral de instalação de inspetorias regionais, visita às áreas indígenas, edificação dos postos indígenas e formas de tratar com estes povos.

Diante destas considerações, pode-se destacar que no início do século XX, com a República, nos deparamos no Brasil com uma ação governamental protecionista, embasada em um pretexto assistencialista, que passa a apresentar restrições aos direitos civis dos indígenas. É o que se observa do Código Civil Brasileiro de 1916, que equiparava os indígenas aos menores de idade (entre 16 a 21 anos), ao determinar que estes, denominados de silvícolas ${ }^{3}$, eram relativamente incapazes para realizarem certos atos (Código Civil de 1916, artigo $6^{\circ}$ ) e que estavam, portanto, sujeitos a um regime tutelar.

Assim dispunha o Artigo $6^{\circ}$ do Código Civil de 1916:

\footnotetext{
${ }^{3}$ Hoje, de acordo com a CF de 1988 e os novos Tratados e Convenções Internacionais, não mais se admite vocábulos de cunho pejorativo.
} 
São incapazes, relativamente a certos atos (art. 147, I) ou à maneira de os exceder. (...) III - os silvícolas.

Parágrafo Único. Os silvícolas ficarão sujeitos ao regime tutelar, estabelecido em leis e regulamentos especiais, o qual cessará à medida que se forem adaptando à civilização do País.

O próprio jurista Clóvis Bevilacqua, autor do projeto do Código Civil de 1916, emprega o termo silvícolas "aos habitantes da selva", sendo restrito a eles o regime de incapacidade jurídica relativa. Os atos aos quais os indígenas estão incapacitados de praticar são os atos jurídicos, cuja definição encontra-se no Art. 81 (Código Civil, 1916) como "todo ato lícito, que tenha por fim imediato adquirir, resguardar, transferir, modificar ou extinguir direitos". Sendo o ato jurídico anulável "por incapacidade relativa do agente" (Art. 147, I).

O Serviço de Proteção aos Índios (SPI) foi extinto em 5 de dezembro de 1967 e substituído pela Fundação Nacional do Índio (FUNAI), através do Decreto-Lei 5.371. Em vários aspectos, o novo órgão indigenista não iria diferir muito do antigo SPI, pois, mesmo com a extinção do SPI, a política indigenista continuava atrelada cada vez mais aos interesses que não visavam beneficiar os povos indígenas. Como exemplo, a questão da ocupação tradicional das terras indígenas.

Com a extinção do SPI, o governo ditatorial civil-militar passou a conceber a figura da Reserva Indígena como uma forma de lidar com o que denominavam de "problema indígena". Pequenas áreas foram, então, destinadas para "acomodar"4 diversos povos, mas não necessariamente situadas em seus territórios de ocupação tradicional.

Assim, a FUNAI veio para resolver o que o regime ditatorial civil-militar concebia como questão indígena brasileira, qual seja, a presença de grupos étnicos populacional e culturalmente diferenciados, os quais controlavam vastos territórios, ao mesmo tempo em que não apresentavam condições de se desenvolver nos moldes propostos pelo regime vigente. A resolução do problema, no entendimento do órgão indigenista, só

\footnotetext{
${ }^{4}$ Brand (1997), enfatiza que para os Kaiowá e Guarani em Mato Grosso do Sul, as reservas significaram o seu confinamento.
} 
poderia vir com a integração dessas populações com a maioria nacional, o que significaria a dissolução de etnias que haviam sobrevivido até então e que, assim, liberariam as terras indígenas para a ocupação de terceiros.

Apesar de uma aparente inovação, a FUNAI carregaria consigo resquícios da política integracionista e assimilacionista, como se pode observar da leitura do Art. $1^{\circ}$, I, da Lei n. 5.371, de 5 de dezembro de 1967, que autoriza a instituição da FUNAl e dá outras providências, com as seguintes diretrizes:

Respeito à pessoa, às instituições e às comunidades indígenas; preservação da cultura e do equilíbrio biológico do índio; garantia da aculturação espontânea, evitando-se transformações abruptas na evolução socioeconômica, exclusividade de usufruto dos seus recursos naturais. (Art. $1^{\circ}$, I, Lei $n^{\circ} 5 \cdot 371 / 67$ )

É importante contextualizar que a FUNAI nasce no bojo de um pensamento desenvolvimentista que vigorará durante toda a década seguinte, em que a ideia do “milagre brasileiro" e do "desenvolvimento" destituía qualquer iniciativa que não estivesse vinculada ao "progresso", sendo que os povos indígenas representavam obstáculos frente a este pensamento.

Nessa perspectiva, o sistema jurídico republicano, desde suas origens, se sustentou sob uma mesma matriz, assumindo-se como o único referencial de normatividade válido e superior. As Repúblicas latino-americanas, particularmente a brasileira, se erigiram assentadas sobre o mesmo substrato, reeditando a diferença racial que recebeu o nome de "colonialismo interno" 5

Entretanto, a ficção de um Estado homogêneo se faz cada vez mais insustentável, e, o que nos últimos anos se intenta cobrir com expressões de liberalismo jurídico, na realidade, não é senão outra forma de seguir tentando anular o indígena por meio da colonização, especialmente a jurídica.

Ordoñez Cifuentes destaca:

\footnotetext{
${ }^{5}$ Nesse sentido, ver Pablo González Casanova, (2007).
} 
[...] el modelo del Estado-nación, heredado de los revolucionarios franceses, ha entrado en una profunda e irreversible crisis y ha dejado de servir como desiderátum de una organización política acorde con los tiempos que vivimos. (CIFUENTES, 2006, p. 45)

Segundo Tubino (2004), o Estado-Nação é um modelo político de Estado, construído em um contexto histórico europeu do século XIX. Ali, a nação emerge como uma construção ideológica, expressa na vontade de consolidar um sentimento de existência e de ser reconhecida enquanto identidade coletiva, associada a uma língua, a uma visão de mundo e a uma cultura determinada. Segundo o autor, o Estado utiliza o mito e o discurso de Nação para reforçar sua vontade de existir.

No caso brasileiro, a ideia de nação, veiculada na primeira metade do século XX entre os intelectuais, como Oliveira Viana e Gilberto Freyre, sustentou por um longo tempo o pilar fundamental de um discurso que imaginava o Brasil miscigenado, diante de constantes correntes humanas que por aqui transitaram direta ou indiretamente, e que isso consistiria num verdadeiro melting-pot tropical, erigido sob o sangue de brancos, indígenas e negros. Ensaiava-se um caráter tropical da formação da nacionalidade, ao mesmo tempo em que se apresentava a identidade como múltipla e única, dando sentido a tudo aquilo que não pudesse ser definido por conceitos. Esses conceitos contribuíram por fundamentar o ideal social brasileiro de que existiria uma sociedade homogênea, pautada pelos mesmos referenciais, capaz de assimilar categorias consideradas como mais adequadas para compor a Nação brasileira (STEFANES PACHECO, 2004).

Os Estados nacionais modernos não se organizaram a partir de uma cultura nacional já existente; ocorreu o processo inverso. Os Estados criaram uma cultura comum nacional entre as diversas nacionalidades já existentes para abranger os diferentes com base em um imaginário passado e futuro comum. Assim, a nação foi e é pensada como uma "comunidade imaginada" (Andersen, 1986), uma construção social, em que a língua nacional, a história nacional e o projeto nacional somente podem ser a língua, a história e o projeto dos grupos socialmente dominantes. 
Porém, sabe-se que este projeto idealizado de Estado-Nação não logrou êxito, pois, as sociedades, os povos, continuam a reivindicar a diferença com base na etnicidade ${ }^{6}$. Assim, na América Latina, a opção intercultural aparece como uma alternativa ético-política frente ao fracasso do assimilacionismo ${ }^{7}$ homogeneizante dos Estados nacionais. Entretanto, não há possibilidade de um paradigma intercultural se não houver quebra de hierarquias e padrões discriminatórios.

\section{O indígena e sua representação frente ao Estado-Nação}

“os índios não são mais o que vocês pensam!”8

É de se evidenciar que, de acordo com o Censo realizado em 2010, do Instituto Brasileiro de Geografia e Estatísticas (IBGE), o Brasil tem aproximadamente 896,9 mil indígenas em todo o território nacional, somando a população residente tanto em terras indígenas (63,8\%) quanto em cidades (36,2\%). O Censo de 2010 investigou pela primeira vez o número de etnias indígenas, encontrando aproximadamente 305. Enfatiza-se que este é apenas um dos indicadores populacionais.

A presença e atuação indígenas cada vez mais visíveis e marcantes, tanto nos cenários políticos nacionais, quanto internacionais, especialmente a partir dos anos 1980, demonstram que estes povos e suas ações estão inseridos em nosso cotidiano e que estas ações causam impactos nas estruturas das sociedades como "um todo".

Tal posicionamento nega a postura assimilacionista que pregava o suposto e inevitável fim das populações indígenas por meio do processo que denominaram de aculturação ${ }^{9}$ e negação de sua identidade étnica. Segundo Almeida (2010), essa visão de

\footnotetext{
${ }^{6}$ A reivindicação da diferença pode ser compreendida enquanto a demanda pela etnicidade, que está estritamente relacionada com a noção de autoidentificação, que pode ser um ato voluntário de pessoas ou comunidades que ao possuírem um vínculo cultural, histórico, político, linguístico ou de outro tipo qualquer, decidem identificar-se como membros de um povo.

${ }^{7} \mathrm{~A}$ abordagem assimilacionista parte do princípio de que todos se integrem à sociedade e se incorporem a uma cultura hegemônica.

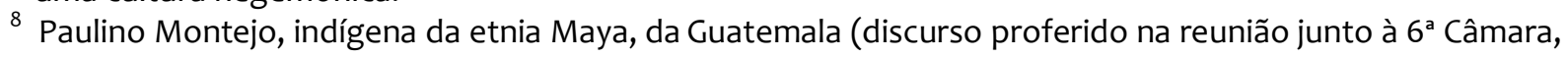
realizada em Brasília, Distrito Federal, 2005).

9 Essa perspectiva vinculava-se a uma simplificação hierarquizante das culturas, assim como seu
} 
que os indígenas estavam inevitavelmente fadados a se integrar na sociedade nacional, destituindo-se de sua cultura ancestral, foi o viés ideológico que percorreu a maioria das políticas públicas desde o século XVIII:

A política assimilacionista para os índios, iniciada com as reformas pombalinas em meados do século XVIII, teve continuidade no Império brasileiro e também na República. Ainda que diferentes legislações garantissem as terras coletivas e alguns outros cuidados especiais para os índios enquanto eles não fossem considerados civilizados, a proposta de promover a integração e extingui-los como grupos diferenciados iria se manter até a constituição de 1988. (ALMEIDA, 2010, p. 18)

É importante não olvidar toda a política exercida pelo Estado brasileiro para com estes povos. A título de exemplo, José Bonifácio, ministro do Brasil independente, apresentou à Assembleia Constituinte de 1823 um projeto para “domesticar" os povos indígenas do Império do Brasil, erradicando a indianidade dos mesmos. Nas palavras de José Bonifácio Andrada e Silva:

[...] seu aspecto de povos vagabundos, e dados a contínuas guerras, e roubos; ... [sem] freio algum religioso, e civil, que coíba, e dirija suas paixões; ... entregues naturalmente à preguiça ... [à] sua gula desregrada... [acham] ser lhes mais útil roubar-nos que servir-nos. (ANDRADA e SILVA apud RAMOS, 2000, p. 267)

Conforme descreve Ramos (2000, p.270), a ânsia de José Bonifácio era erradicar a indianidade dos índios, “domesticá-los e fazê-los felizes”. A autora argumenta que a proposta de José Bonifácio expressa um “clima de opinião" que estava de acordo com a estrutura estatal e patrimonial que o Brasil recebeu de seus colonizadores e que adaptou ao seu próprio estilo. Para a autora, “longe de ser irrelevante, o projeto de José Bonifácio, perfeitamente à vontade na linha sucessória de experimentações indigenistas, ajuda-nos a entender melhor a política e a prática atuais no lidar com a etnicidade no país" (RAMOS, 2000, p.267). 
Observa-se que, dada a visibilidade política que as populações indígenas vêm conquistando, novas considerações devem ser feitas e estas passam cada vez mais pela necessidade de se reconsiderar a maneira de pensar a noção que a sociedade não indígena tem dos povos indígenas. Ademais, os pressupostos para se compreender a “questão indígena" ${ }^{10}$ vão além das oposições entre vencedores ou vencidos, dominantes e dominados e que acabam deixando para os povos indígenas apenas dois papéis: os de vítimas de aniquilação ou de mártires da conservação da cultura, "presos" a um essencialismo.

Chamorro (2015, p. 233), destaca que “os povos indígenas não são melhores nem piores que os não indígenas. São humanos e, em certas situações, podem ser tão bons ou ruins como nós outros." A autora ainda acrescenta que:

a diferença entre eles e nós é de perspectiva ou cosmológica, no sentido de eles interpretarem o mundo presente e "real" a partir dos primórdios ou referências míticas e no sentido de eles não estarem de fato- ou apenas marginalmente - inseridos na sociedade de mercado, no sistema capitalista. Em geral, seus sistemas sociais desconhecem a centralização política e se orientam por economias de reciprocidade, o que levou muitos estudiosos a denominar equivocadamente, as sociedades indígenas de sociedades primitivas, como, por exemplo, nas diversas vertentes das teorias evolucionistas e positivistas. (CHAMORRO, 2015, p. 233)

No Brasil, o desconhecimento ou desprezo pelo papel da diversidade cultural no estímulo e enriquecimento das dinâmicas sociais e, principalmente, a recusa etnocêntrica da contemporaneidade de sociedades, povos de orientação cultural diversa, tem sedimentado uma "sensibilidade de mundo" quase sempre negativa dos povos indígena ${ }^{11}$.

\footnotetext{
${ }^{10} \mathrm{O}$ uso do termo "questão indígena" entre aspas diz respeito ao fato de não se tratar de uma questão propriamente dos povos indígenas, mas de um problema criado pela sociedade nacional. Bárcenas (2005), já aduzia que: a "questão não é indígena”, mas sim da sociedade não indígena.

${ }^{11}$ Recorre-se à expressão utilizada por Mignolo (2014, p. 31) que prefere destacar "sensibilidad del mundo" no lugar de "visión del mundo", pois, segundo o autor, o conceito "visión" é um conceito privilegiado na epistemologia ocidental.
} 
Existe uma postura ideológica predominante de que os povos indígenas não contavam ou não contam para o nosso futuro, uma vez que muitos os consideram como uma excrescência arcaica, marcados por uma perspectiva de fatalidade de extinção dessas sociedades (BÁRCENAS, 2005).

Para contextualizar este tema, merece destaque a fala do líder indígena Paulino Montejo, pertencente à etnia Maya, da Guatemala, que em um discurso proferido na reunião junto à $6^{\text {a }}$ Câmara, realizada em Brasília, Distrito Federal, apresentou, a partir de suas experiências de vida, relatos decorrentes da estigmatização do que se espera de "um índio genérico", reificado no tempo, por parte da sociedade não indígena, argumentando que: “os índios não são mais o que vocês pensam!”, ou seja, a imagem que a sociedade não indígena tem destes povos não corresponde à cotidianidade indígena. Nesse sentido, Paulino denuncia em seu discurso a dificuldade de lidar com as diferenças e enfatiza que "os supostos multiculturalismos (religioso, jurídico e epistemológico)", devem ser analisados com cuidado, pois, estes referenciais muitas vezes mantêm suas próprias contradições discursivas ${ }^{12}$.

Montejo argumentou a respeito da dificuldade que paira sobre muitas academias em perceber os povos indígenas enquanto atores históricos, com identidades e culturas distintas, pois, segundo ele - "ainda se encontram num indigenismo romântico da década de 1960." Paulino Montejo também destacou que a orientação da política indigenista atual é apresentada como um processo de continuidade de um projeto assimilacionista e colonialista, incluindo as políticas assistencialistas, como exemplo, "a distribuição de cestas básicas pelo órgão indigenista FUNAI, que têm servido para enfocar o indigenismo enquanto instrumento de controle dos povos indígenas, tanto na teoria, quanto na prática".

Acrescentou em seu discurso o tema da importância da participação dos povos indígenas na formulação das políticas e que estas também devem ser pensadas por estes povos - "os verdadeiros interessados" -, e finalizou seu discurso destacando a

\footnotetext{
${ }^{12}$ Apesar de ser um discurso proferido há alguns anos (2005), entendo que ele continua atual e foi este discurso que me impulsionou a pensar a "questão" da identidade indígena e suas demandas diante do Estado brasileiro.
} 
importância de se escutar neste processo as "autoridades" indígenas, pois: "Os índios já têm condição de falar por si."

Neste sentido, Linda Tuhiwai Smith, pesquisadora e indígena Maori da Nova Zelândia corrobora:

Una de las características de los pueblos indígenas era que no podíamos usar nuestra mente o nuestro intelecto. No podíamos inventar cosas, no podíamos crear instituciones ni historia, no podíamos imaginar, no podíamos producir nada de valor, no sabíamos usar la tierra ni otros recursos del mundo natural, no practicábamos "las artes" de la civilización (...) En otras palabras, no éramos "completamente humanos". (TUHIWAI SMITH, 2016, p. 51)

\section{As demandas indígenas e o Estado}

As demandas indígenas avançam em um processo desafiador, uma vez que confrontam os padrões culturais existentes de poder centralizado e põem em questão muitos dos modos pré-concebidos de análise.

De acordo com Bárcenas:

Estamos ante el hecho de que los pueblos indígenas no sólo existen, sino que también se mueven y en muchos casos lo hacen fuera de los espacios institucionalizados por los Estados de los que forman parte, creando sus propios rostros y rumbos.

(...)

Esto desconcierta a la clase política tradicional, porque los movimientos indígenas no son cualquier movimiento, sino unos que dentro de su utopía incluyen modificar el actual estado de cosas por otro que ensanche los espacios de participación en la vida política del país, al tiempo que amplíe las vías para hacerlo, dando origen, de esa manera, a nuevos movimientos sociales. (BÁRCENAS, 2005, p. 15)

Para uma melhor compreensão das demandas indígenas, necessário se faz o entendimento de que este processo é político, sendo esse político interpretado de modo mais eficaz, como um tipo de relação que pode se desenvolver em qualquer área do 
social, independente de se permanecer ou não dentro do recinto institucional da política. O político, segundo Slater (2000) é um movimento vivo, um tipo de "magma de vontades em conflito" ou antagonismos; ele é móvel e ubíquo, indo além, mas também subvertendo os cenários e amarras institucionais da política.

O surgimento de mobilizações e manifestações indígenas no Brasil está diretamente relacionado com os movimentos étnicos que, a partir da década de 1970, emergem em diversos países da América Latina. No Brasil, foi basicamente a partir desta década (1970) que as diversas mobilizações indígenas alcançaram repercussão junto à opinião pública nacional e internacional. Neste momento, alguns setores da sociedade acreditavam que o fim desses povos era iminente. Foi nesse contexto e na expectativa de se insurgir contra todo esse quadro desfavorável que os povos indígenas iniciaram um intenso e profundo processo de articulações, fortalecimento da autoestima e organização das lutas.

Como bem esclarece Pacheco de Oliveira (2016),

As vozes indígenas contra a colonização só se fizeram conhecer recentemente, nas últimas décadas, quando as lutas por demarcação de seus territórios, ampliadas e repercutidas por um arco de alianças (igrejas, universidades, grupos de direitos humanos), começaram a chegar até a opinião pública, em aberta contradição com as imagens idealizadas sobre a construção do país e com a postura tutelar do indigenismo. Foi este, no final da década de 1970, o momento em que, creio, iniciou-se tal ruptura. (OLIVEIRA, 2016, p. 13)

Assim, na década de 1980, com o crescente processo de organização e de articulação dos povos indígenas, aumentou a participação destes povos em diversas instâncias, com afirmações e alianças com diversos segmentos da sociedade civil e com setores populares que procuravam se reorganizar.

Stavenhagen enfatiza:

Los pueblos indígenas han surgido como nuevos actores políticos y sociales en América Latina en años recientes, o más bien, como dirían 
algunos, como nuevo sujeto histórico. Con esto significamos que los índios se transforman en activos en vez de continuar siendo objetos "pasivos" del cambio histórico". (STAVENHAGEN, 1997, p. 13)

Ademais, se observa que, além de estreitarem alianças, os povos indígenas desencadearam ações conjuntas e cooperações com Igrejas, organizações não governamentais, entidades de apoio à causa indígena, entre outros. Desta forma, o movimento experimentaria variadas formas de organizações.

De acordo com Neves (2003):

O movimento indígena brasileiro é mais do que uma resposta meramente reativa às condições e estímulos externos. [...] Deve-se ter em mente que os povos indígenas têm uma longa experiência de andar alinhados em trilhos sinuosos. O que para um pensamento ocidental podem parecer desvios à toa, pode verdadeiramente representar o caminho mais curto entre dois pontos, proporcionando-nos lições inesperadas de produtividade. (NEVES, 2003, p. 17)

Além do que se pode observar em um mundo globalizado e pluricultural ${ }^{13}$ é que a “irrupção" dos povos indígenas e sua agenda de direitos é um fenômeno que não fica circunscrito ao Brasil ou América Latina, mas faz parte de um processo global, de uma diversidade de lutas pelo reconhecimento e pela dignidade humana. Conforme destaca a CEPAL (Comissão Econômica para a América Latina e o Caribe): "La tenaz resistencia de los pueblos indígenas se expresa en la actualidade en la instauración de nuevos status quo políticos y territoriales así como de nuevos modos de relación institucional de los Estados y los pueblos indígenas." 14

É necessário destacar que em relação às mobilizações étnicas contemporâneas e à discussão muitas vezes apregoada de que se trata de mobilizações separatistas, que

\footnotetext{
13 Sobre pluriculturalidade, ver Fajardo (2004), Bárcenas (2005), Cifuentes (2006), Tuhiwai Smith (2016), Pacheco de Oliveira (2016).

${ }^{14}$ CEPAL, (Comissão Econômica para América Latina e o Caribe, 2014). Los pueblos indígenas en América Latina. Avances en el último decenio y retos pendientes. Disponível em: <http://www.cepal.org/ptbr/publicaciones/37773-os-povos-indigenas-na-america-latina-avancos-na-ultima-decada-e-desafios >. Acesso em: 20 de agosto de 2017.
} 
intentam reverter a soberania dos Estados nacionais, Salinas Cañas (2016, p. 178), afirma que grande parte destas mobilizações são "intentos grupales”, que visam assegurar um grande nível de recursos dos Estados e obter uma maior participação política, porém, não desejam se tornar independentes dos governos nacionais. Para o autor, estas mobilizações se associam com a problemática de definir o tema da autonomia territorial, mas não da soberania, com vistas ao separatismo.

Para exemplificar, Salinas Cañas (2016) cita o movimento zapatista, formado por camponeses e indígenas mexicanos que defendem uma gestão mais democrática do território, originado na região de Chiapas em 1994, cujos encaminhamentos e demandas, que incluem protestos, caminhadas, fechamento de rodovias, dentre outros instrumentos de mobilização, tentam comunicar que suas intenções são com vistas ao respeito à pluralidade, consideradas enquanto "integradoras" e não separatistas, o que pode ser identificado na frase: “Nunca más un México sin nosotros".

\section{Apontamentos finais}

Los movimientos contemporáneos son profetas del presente. Lo que ellos poseen no es la fuerza del aparato, sino el poder de la palabra. Anuncian los cambios posibles, no el futuro distante sino el presente de nuestras vidas; obligan a los poderes a mostrarse y les dan forma y rostro; utilizan un lenguaje que parece exclusivo de ellos, pero dicen algo que los trasciende y hablan por todos nosotros. (ALBERTO MELUCCI, apud BÁRCENAS, 2005)

Por certo, as mobilizações indígenas têm contribuído para modificar a imagem de uma América Latina que não está de acordo com a pretensa uniformidade que outrora foi pensada para este território. Mesmo diante de uma situação considerada assimétrica entre os povos indígenas e as ações colonizadoras, é de se notar que estes povos se tornaram visíveis e que não é mais possível ignorá-los. 
A emergência nos últimos anos das mobilizações indígenas na América Latina tem posto em evidência aspectos decisivos da compreensão dominante nos sistemas políticos, jurídicos e culturais desses países.

Inicialmente, pode-se apontar o desencanto com a concepção iluminista de outrora. Conforme destacado no decorrer do trabalho, certos conceitos arraigados no pensamento ocidental passam a ser questionados, ou seja, os limites que a construção de um Estado-Nação, que era pensado como homogêneo, monocultural, monolinguístico, centralizador, baseado na assimilação dos povos, deixa de existir. Também é de se considerar o surgimento de "novos" sujeitos políticos e coletivos, que estão organizados e dotados de sentidos e discursos de ações, que hoje se traduzem por movimentos étnicos culturais.

Um exemplo disso é que na atualidade, as mobilizações indígenas não podem ser consideradas como uma mera exteriorização de identidades étnicas primordiais dadas; nem um mero "retorno" a uma etnicidade que remonta a tempos imemoriais. Ao contrário, são complexos processos de construção política de identidades.

O conceito de identidade étnica aqui aludido diz respeito à concepção apresentada por Poutignat e Streiff-Fenart (2011, p. 84), que defendem a autodefinição baseada em pressupostos subjetivos como elemento-chave para a compreensão das diferenças. Além do que, conforme destaca Frederick Barth (2011, p. 189/199), um grupo não se autoidentifica de forma isolada, sem a presença de interação social.

Para Barth (2011), o sentimento de pertença étnica é constantemente reelaborado e instituído de forma dinâmica por meio de processos endógenos e exógenos, não evitando, contudo, que ocorram casos em que a nomeação exógena se sobreponha a todos os processos de etiquetagem e rotulações internas. Assim, de caráter fluído, os processos identitários se coadunam como parte integrante da constituição de um modelo autorrepresentativo baseado na diferença ativa dos povos indígenas.

Destaca-se que o reconhecimento dos direitos dos povos indígenas na América Latina durante as últimas décadas, tanto nas Constituições, quanto nas demais legislações, pode ser explicado graças ao crescente envolvimento desses povos e de suas 
organizações no cenário político dos Estados. Estes povos lentamente começaram a “desnudar” a situação a que foram submetidos na construção do Estado Nacional e passaram a reconstruir um novo cenário, em que o respeito à pluralidade étnica deve estar incluído.

Entende-se que, cada vez mais, comunidades reivindicam espaços de interlocução, e, dentro de um contexto maior, qual seja, global, as comunidades se organizam de acordo com suas especificidades. $\mathrm{E}$, neste conjunto, os povos indígenas querem ser escutados a partir de um lócus determinado, enquanto indígenas, pois, participam de um processo histórico que, ao contrário do que já foi prognosticado, apresenta-se como um campo aberto de possibilidades. Os povos indígenas, portanto, abrem vias plurais para uma reflexão necessária na compreensão de profundas mudanças em relação aos "povos e Estado".

Rodriguez Mir (2008 apud Salinas Cañas, 2016), em um estudo sobre os movimentos indígenas na América Latina, acentua que as demandas são comuns a todos os povos indígenas, especialmente porque sofrem basicamente dos mesmos problemas e obstáculos para a concretização de seus direitos (Rodriguez Mir, 2008 apud Salinas Cañas, 2016, p. 178).

Diante destas considerações, compreende-se que o estudo deste tema é de fundamental importância face aos novos desafios propostos à sociedade contemporânea, com novas demandas, vistas à interculturalidade, e, um perfil inovador, ancorado na dignidade da pessoa humana tal qual propõe a Magna Carta brasileira, bem como os demais acordos, convenções e tratados internacionais dos quais o Brasil é signatário.

E, ademais, conforme propõe Bárcenas:

El final de estos procesos nadie lo conoce. Lo que es cierto es que son procesos sin retorno al pasado. Porque su apuesta es por el futuro. Por un tipo de desarrollo que ponga en el centro a los pueblos y a las gentes que los habitan. (BÁRCENAS, 2005, p.124) 


\section{Referências}

ALMEIDA, Maria Regina Celestino de. Os Índios na história do Brasil. Rio de Janeiro: Editora da FGV, 2010.

ANDERSEN, Benedict. Imagined communities: reflections on the origins and spread of nationalism. Norfolk: Verson Editions, 1986.

ARENDT, Hannah. O sistema totalitário. Tradução de Roberto Raposo. Lisboa: Publicações Dom Quixote, 1978.

BÁRCENAS, Francisco Lopez. Rostros y caminos de los movimientos indígenas en México.Ciudad de México: MC editores, 2005.

BARTH, Fredrik. Grupos Étnicos e suas fronteiras. In: POUTIGNAT, Philippe; STREIFFFENART, Jocelyne (Orgs.). Teorias da Etnicidade. São Paulo: Editora da Unesp, 2011. p. 2567.

BRAND, Antonio J. O impacto da perda da terra sobre a tradição Kaiowá/ Guarani: os difíceis caminhos da palavra. 1997. Tese (Doutorado) - Pontifícia Universidade Católica do Rio Grande do Sul, Porto Alegre.

CEPAL. Los pueblos indígenas en América Latina: avances en el último decênio y retos pendientes para la garantia de sus derechos. Santiago: Naciones Unidas, noviembre de 2014. Disponível em: < http://www.cepal.org/pt-br/publicaciones/37773-os-povosindigenas-na-america-latina-avancos-na-ultima-decada-e-desafios> .Acesso em: 20 de agosto de 2017.

CHAMORRO, Graciela. História Kaiowa: das origens aos desafios contemporâneos. São Bernardo do Campo: Nhnaduti Editora, 2015.

CIFUENTES, José Emilio Ordoñez. El aporte doctrinario de la antropología crítica latinoamericana y sus premisas socio-jurídicas. Colección Legislando la agenda social: Política indígena del reconocimiento de la diferencia al fin de la desigualdade. Ciudad de Mexico: Centro de Estudios Sociales y de Opinión Pública, Cámara de Diputados / LIX Legislatura, 2006.

CLAVERO, Bartolomé. Derecho indígena y cultura constitucional en América: Siglo XXI: México, 2009.

CUNHA, Manuela Carneiro da. (Org.). Legislação Indigenista no século XIX: Uma 
compilação 1808-1889. São Paulo: Editora da Universidade de São Paulo: Comissão Pró Índio, 1992.

FAJARDO, Raquel Yrigoyen. Vislumbrando un Horizonte Pluralista: Rupturas y Retos epistemológicos y políticos. In: CASTRO, Milka. Los desafios de la interculturalidad: identidad, política y derecho. Santiago, Chile: LOM ediciones, 2004.

GONZÁLES CASANOVA, Pablo. Colonialismo interno (uma redefinição). In: BORON, A. , A.; AMADEO, J; GONZALEZ, S. (Orgs). A teoria marxista hoje: problemas e perspectivas. Buenos Aires: Consejo Latinoamericano de Ciencias Sociales-CLACSO, 2007.

MIGNOLO, Walter et. al.. Retos decoloniales, hoy. In: BORSANI, María Eugenia; QUINTERO. Pablo (Comp.). Los desafíos decoloniales de nuestros días: pensar en colectivo. Neuquén: EDUCO - Universidad Nacional del Comahue, 2014.

MONTEJO, Paulino. Curso preparatório: a antropologia no Ministério Público Federal e a Defesa dos Direitos Socioculturais. Março de 2005. Disponível em: http://www.mpf.mp.br/atuacao-tematica/ccr6/eventos/2005/relatorio.pdf. Acesso em 20 de julho de 2017.

NEVES, Lino João de Oliveira. Olhos mágicos dos Sul (do Sul): lutas contra hegemônicas dos povos indígenas no Brasil. In: SANTOS, Boaventura de Souza. (Org.). Reconhecer para libertar: os caminhos do cosmopolitismo multicultural. Rio de Janeiro: Civilização Brasileira, 2003.

OLIVEIRA, João Pacheco de. O nascimento do Brasil e outros ensaios: "pacificação", regime tutelar e formação de alteridades. Rio de Janeiro: Contra Capa, 2016.

POUTIGNAT, Philippe; STREIFF-FENART, Jocelyne. Teorias da etnicidade: seguido de grupos étnicos e suas fronteiras de Fredrik de Barth. São Paulo: Editora da UNESP, 2011.

SALINAS CAÑAS, Sergio. Conflictos y nuevos movimientos sociales. Santiago, RIL Editores, 2016.

SARLET, Ingo Wolfgang. Dignidade da pessoa humana e direitos fundamentais na Constituição Federal de 1988. 10 ed. Porto Alegre: Livraria do Advogado, 10 a ed. 2015.

SLATER, David. Repensando as espacialidades dos movimentos sociais. In: ÁLVARES, Sonia E.; DAGNINO, Evelina; ESCOBAR, Arturo. Cultura e política nos movimentos sociais latino americanos: novas leituras.Belo Horizonte: Ed. UFMG, 2000. 
STAVENHAGEN, Rodolfo. Las organizaciones indígenas: actores emergentes en America Latina. In: GUTIERREZ ESTEVEZ, Manuel (Comp.). Identidades Étnicas. Madrid: Casa de América de Madrid, 1997.

STAVENHAGEN, Rodolfo. Los pueblos originários: el debate necesário. $1^{\mathrm{a}}$ ed. Buenos Aires; CTA Ediciones: CLACSO, 2010.

STEFANES PACHECO, Rosely A. Mobilizações Guarani - Kaiowá, Ñandeva e a (Re)construção de Territórios: (1978-2002) novas perspectivas para o direito indígena. 2004. Dissertação (Mestrado em História) - Universidade Federal de Mato Grosso do Sul, 2004 .

SOUZA FILHO, Carlos Frederico Mares. Terra mercadoria, terra vazia: povos, natureza e patrimônio cultural. Insurgência: Revista de Direitos e Movimentos Sociais, v. 1, n. 1, 2015.

SOUZA FILHO, Carlos Frederico Mares de. 0 renascer dos povos indígenas para o direito. Curitiba: Juruá, 2000.

TUBINO, Fidel. La Impostergable Alteridad: del Conflicto a la Convivencia Intercultural. In: CASTRO, Milka. Los Desafios de la Interculturalidad: identidad, política y derecho. Santiago, Chile: LOM ediciones, 2004.

TUHIWAI SMITH, Linda. A descolonizar las metodologias: investigación y pueblos indígenas. Trad. Katryn Lehman, $1^{\mathrm{a}}$ ed. Santiago, Chile: LOM ediciones, 2016. 